NASA Technical Memorandum 101491

\author{
Highlights of Experience with a Flexible \\ Walled Test Section in the NASA \\ Langley 0.3-Meter Transonic Cryogenic Tunnel
}

\author{
(NASA-TM-1014S1) HIGELIGHTS CF EXPEBIEACE \\ N89-10060 \\ HIH A FIEXIBIE LALIED TEST SECTICA IN THE \\ MASA IANGLEY C. E-EETEF TRALSCNIC CBYOGENIC \\ TUABEL (NASA) $12 \mathrm{~F}$ \\ CSCL $14 \mathrm{H}$ \\ $\begin{array}{ll}\text { G } 3 / 09 & \text { Unclas } \\ 0167512\end{array}$
}

Stephen W. D. Wolf

Vigyan Research Associates, Inc.

Hampton, Virginia

Edward J. Ray

Langley Research Center

Hampton, Virginia 


\title{
HIGHLIGHTS OF EXPERIENCE WITH A FLEXIBLE WALLED TEST SECTION IN THE NASA LANGLEY 0.3-METER TRANSONIC CRYOGENIC TUNNEL
}

\author{
Stephen W. D. Wolf" and Edward J. Ray" \\ NASA Langley Research Center \\ Hampton, Virginia
}

\section{Abstract}

The unique combination of adaptive wall technology with a continuous flow cryogenic wind tunnel is described. This powerful combination allows wind tunnel users to carry out two-dimensional (2-D) tests at flight Reynolds numbers with wall interferences essentially eliminated. We highlight validation testing to support this claim using well tested symmetrical and cambered airfoils at transonic speeds and high Reynolds numbers. We briefly describe the test section hardware which has four solid walls, with the floor and ceiling flexible. We outline the method of adapting/shaping the floor and ceiling to eliminate top and bottom wall interference at its source. The highlights of our testing experience involve discussion of data comparisons for different size models tested by us and others in several sophisticated 2-D wind tunnels. In addition, we examine the effects of Reynolds number, testing at high lift with associated large flexible wall movements, the uniqueness of the adapted wall shapes and the effects of sidewall boundary layer control. Our 2 years of operational experience with the adaptive wall test section hardware and its associated control system has taught us important lessons about design and operating procedures. We conclude that the $0.3-\mathrm{m}$ TCT is now the most advanced 2-D research facility anywhere.

\section{Nomenclature}

$\alpha \quad$ Angle of attack

c Model chord

Cd Drag coefficient

Cd Minimum drag coefficient

$\mathrm{Cn}^{\min }$ Normal force coefficient

Cn Maximum normal force coefficient

$\mathrm{Cp}^{\max }$ Pressure coefficient

Rc Chord Reynolds number, per foot

w Test section half width

$x \quad$ Streamwise location downstream of airfoil leading edge

$z \quad$ Spanwise location relative to the tunnel centerline

\section{Introduction}

The quest for improved data quality from modern wind tunnels continues to spur the development of innovative testing techniques. One such technique uses an Adaptive Wall Test Section (AWTS) to eliminate 2-D tunnel boundary (top and bottom wall) interference at its source. (This technique is in fact a development of one of the first solutions to transonic wall interferences developed in the $1930 \mathrm{~s}^{1}$ ) This paper discusses the highlights of the unique combination of the adaptive wall testing technique with another innovative technique which uses a continuously operating cryogenic wind tunnel to achieve full scale Reynolds numbers.

We installed an AWTS in the Langley $0.3-\mathrm{m}$ Transonic Cryogenic Tunnel (TCT) in 1985. The cryogenic wind tunnel

\footnotetext{
*Research Associate, Experimental Techniques Branch, Transonic Aerodynamics Division, Member AlAA.

* Senior Research Engineer, Experimental Techniques Branch, Transonic Aerodynamics Division, Member AIAA.
}

This work was done while the first author held a National Research Council - NASA Langley Research Center Research Associateship. itself became operational in 1973 and the AWTS is the third test section installed in this facility. Actually, it was around 1975 when engineers at Langley chose a flexible walled design for the AWTS. They based their decision on NASA sponsored research at the University of Southampton. ${ }^{2}$ This design offered the possibility of eliminating top and bottom wall interference in transonic testing, thereby allowing the use of large models. Researchers intended that this test section should give the $0.3-\mathrm{m}$ TCT sufficient capability to meet all projected chord Reynolds number requirements for 2-D testing, into the foreseeable future.

Since 1975, researchers worldwide have provided a much better understanding of transonic AWTSs and the inherent mechanical complexities. ${ }^{3}$ Some researchers still advocate modifications of the conventional ventilated test sections (called variable porosity test sections), while others have opted for the original 1930s, National Physical Laboratory (NPL) approach using flexible walls in a solid walled test section. It is apparent from the literature that flexible walled AWTSs have demonstrated distinct advantages over variable porosity AWTSs as follows:

a) Flexible walls provide powerful control of the test section boundary shape allowing the testing of large models and high lift conditions.

b) Flexible walls make the transonic test section boundaries aerodynamically simple so adaptation measurements are routine and residual interference assessment is easier.

c) Solid test section walls improve flow quality, reducing tunnel interferences and lowering tunnel operating costs.

d) Flexible walls can be rapidly streamlined.

These advantages are true for both 2-D and 3-D testing. In addition, we now know the modification of ventilated transonic test sections as variable porosity AWTSs does not reduce the test section complexity of an AWTS. In hindsight, our choice of a flexible walled test section is well justified.

The highlights of our experience with the flexible walled AWTS in the $0.3-\mathrm{m}$ TCT form the main substance of this paper. We have carried out validation testing with well tested airfoils (NACA 0012 and CAST 10-2/DOA-2) to examine the testing technique in a new and challenging cryogenic environment. We present airfoil data to support the claim that top and bottom wall interference are eliminated in an AWTS. During these validation tests, we have also extended successful use of AWTSs into the realms of high lift and flight Reynolds number. In addition, we have investigated the effects of test section length truncation to ensure successful testing of large models.

Operationally, we have made several advances. Nonexpert operators have used the AWTS successfully. In effect we have demonstrated that the inherent complexity of AWTSs can be invisible to the user. In addition, we have explored the limitations of our AWTS hardware in terms of capability and measurement accuracy with interesting results.

We intend this report to provide a detailed summary of our 2-D experiences with adaptive wall technology in terms of wind tunnel results and operational aspects. The lessons learnt during our investigations are discussed in the hope others engaged in similar research will benefit. 


\section{Facility Descriotion}

Our description of the $0.3-\mathrm{m}$ TCT is brief; more information is available in the literature. ${ }^{5,8}$ Basically the $0.3-$ $m$ TCT is a continuously operating cryogenic pressure tunnel. We show a sketch of the closed tunnel circuit in figure 1 .

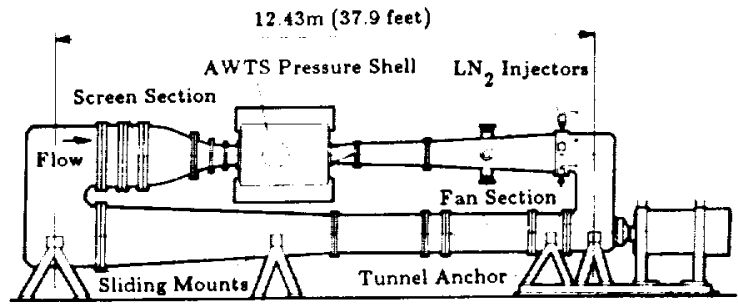

Fig. I Sketch of the 0.3-m TCT tunnel circuit with the AWTS installed.

A variable speed, $2.24 \mathrm{MW}$ electric motor drives the fan. Test section Mach number is continuously variable between 0.2 and about 0.9 , although supersonic testing should be possible using suitable flexible wall shapes. We can vary the stagnation pressure from slightly over 1 bar up to 6 bars and the stagnation temperature from $340 \mathrm{~K}$ down to about $77 \mathrm{~K}$. The test gas is nitrogen. The wide ranges of pressure and temperature allow us to investigate almost a 6 to 1 range in Reynolds number effects. A maximum Reynolds number of over 328 million per meter (100 million per foot) is possible. In addition, we can independently vary either pressure or temperature to achieve the desired Reynolds number. The 0.3-m TCT uses sophisticated systems for Mach number, pressure, and temperature control.

The AWTS ${ }^{7}$ is nominally $33 \mathrm{~cm}$ (13 inches) square and has an effective length of $1.42 \mathrm{~m}$ (55.8 inches). The four walls are solid with only the floor and ceiling flexible. We enclose the complete test section in a pressure shell which forms a $1.86 \mathrm{~m}$ (73.2 inches) long insert into the $0.3-\mathrm{m}$ TCT tunnel circuit (see figure 2).

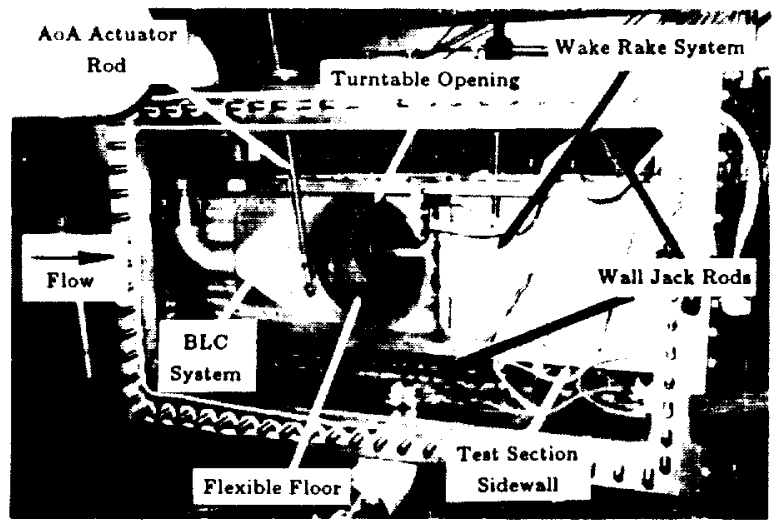

Fig. 2 View of the flexible walled AWTS with the left side of the surrounding pressure shell removed.

A system of 21 jacks supports each flexible wall as shown on the schematic diagram in figure 3 . The length of the flexible walls is $1.82 \mathrm{~cm}$ ( 71.7 inches) with the downstream $40 \mathrm{~cm}$ (15.9 inches) providing a smooth transition from the adaptive portion of the test section to the fixed diffuser. The flexible walls are made of 308 stainless steel. The wall thickness varies along the length of each wall to optimize flexibility and resistance to bending due to pressure load. The volume surrounding the entire test section is vented to the test section downstream of the model to minimize pressure loading on the flexible walls. 0.3-m TCT ADAPTME WALL TEST SECTION

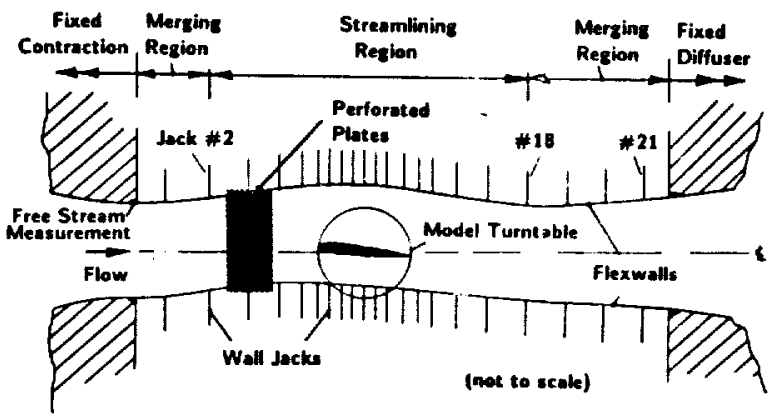

Fig. 3 Schemalic diagram of the flexible walled AWTS.

Individual stepper motors power each wall jack giving a slow wall movement speed of $0.24 \mathrm{~mm}(.009$ inch) per second. A dedicated Modcomp Classic computer (CPU-A) controls the displacement of each jack and measuies the current position of each jack with an individual Linear Variable Displacement Transducer (LVDT) (see figure 4). The LVDTs have an accuracy of $0.127 \mathrm{~mm}$ (.005 inch) over a travel range of $10.16 \mathrm{~cm}$ ( 4 inches). Both the stepper motors and the LVDTs are mounted outside the pressure shell. The jack mechanisms are therefore isolated from the severe cryogenic environment in the test section. Nevertheless during cryogenic operations, there are significant ambient temperature changes around the LVDTs which can cause electrical drift in the instruments. This drift can cause up to $1 \mathrm{~mm}(.040 \mathrm{inch})$ of false jack displacement. The jack mechanisms connect to each jacking point on the flexible walls by a pair of push/pull rods. The associated 84 rods penetrate the pressure shell to attach to the flexible walls. We use two rods per jacking point to minimize unwanted spanwise wall movement.

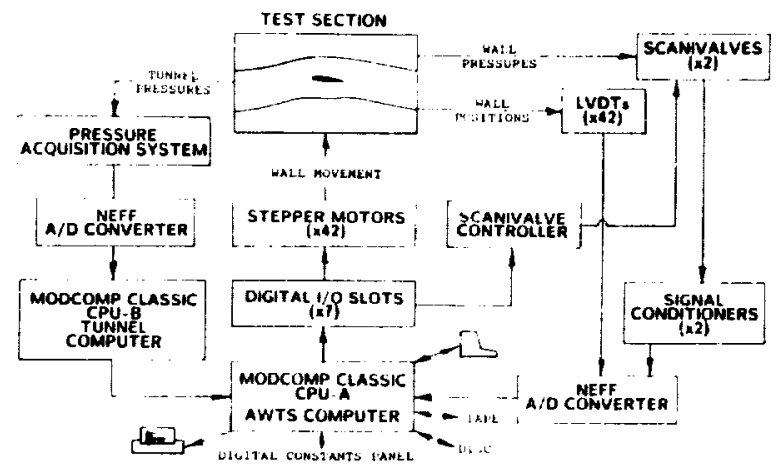

Fig. 4 Overview of the 0.3-m TCT AWTS Control Hardware.

For 2-D wall adaptation, we need only measure wall pressures on the tunnel centerline. For simplicity, we measure wall pressures at only the 17 jacking points per wall within the streamlining portion of the AWTS (see figure 3). A dedicated computer (CPU-A) measures these pressures with two pressure transducers working through two scanivalves (see figure 4). These pressure transducers are capacitive type ${ }^{6}$ and are configured to measure a pressure difference relative to reference pressure, in the range $\pm 138 \mathrm{kN} / \mathrm{m}^{2}\left( \pm 20 \mathrm{lb} / \mathrm{in}^{2}\right)$. These transducers have an accuracy of $\pm 0.25 \%$ of reading. The computer measures the reference pressure with a quartz Bourdon tube pressure gauge which is accurate to better than about $\pm 0.02 \%$ of full scale over the range 1 bar to 6 bars. We measure model and tunnel pressures with similar pressure transducers ${ }^{B}$ under the control of another Modcomp Classic computer (CPU-B) as shown in figure 4 . We measure free stream static pressure at the entrance of the test section as shown in figure 3. 
We can mount a vertical sweep wake rake on the left sidewall at one of three downstream locations. ${ }^{5}$ The rake supports six total head probes positioned along its span between the tunnel centerline and the sidewall. The vertical position of the rake is automatically controlled by CPU-B.

The AWTS has provision for sidewall Boundary Layer Control (BLC) as shown in figures 2 and 3. We can fit porous plates in the rigid sidewalls just upstream of the model location as shown in figure 3. Both active and passive BLC is possible with this advanced system although we only discuss passive BLC data in this paper.

\section{Wall Adaptation}

The wall adaptation process in any AWTS is crucial to successful and practical testing. The process is necessarily iterative 7,8 and generates "corrected" data as shown by the event diagram in figure 5 .

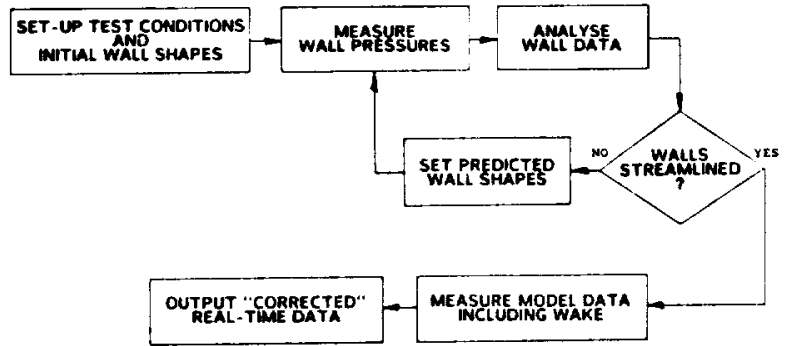

Fig. 5 Sequence of events in the wall adaptation process.

The Analyse Wall Data event refers to the prediction of new wall shapes for streamlining and the calculation of residual wall interferences. The term streamlining requires some explanation. We achieve the elimination of top and bottom wall interference in 2-D testing by making the flexible floor and ceiling of the test section follow streamline shapes that would exist around the model if it were in free air. In effect, we make the presence of the top and bottom walls invisible to the model which then performs as if it were in an infinite flow field. The term streamlining therefore refers to the driving of the flexible walls to streamline shapes.

We use a rapid wall adjustment strategy developed by Judd, Goodyer, and Wolf ${ }^{8,9}$ to predict wall shapes for streamlining. The associated theory is linearised and we introduce the Prandil-Glauert factor for flow compressibility. Strategy computations take less than 1 second per iteration. We consider the condition Walls Streamlined to exist when the modulus of the residual wall interferences reduce below fixed maxima. In the $0.3-m$ TCT these maxima are as follows:

1) Average $C p$ error (between streamline and actual values) along each wall -0.01

2) Induced angle of attack at the model leading edge $-0.015^{\circ}$

3) Induced camber along the model chordline $-0.07^{\circ}$

4) Average induced streamwise $C p$ error along the model chordline -0.007

We determine these maxima empirically as a compromise between perfection (zero residual interference) and minimizing the number of iterations in the adaptation process. The important factor here is overall system quality in terms of instrumentation accuracy, test condition stability, and wall imperfections. We compute these residual interferences using linearised compressible flow theory. We represent the flexible walls by panels of vorticity placed on the aerodynamic contours (wall contours plus boundary layer displacement thicknesses) in an undisturbed potential flow field. The local strength of the wall vorticity is proportional to the local wall $\mathrm{Cp}$ error between the computed streamline value and the actual measured value.
It is obvious to any wind tunnel user that obtaining transonic 2-D "free air" data is more complex using an AWTS than a conventional test section, or is it? Generally, we acquire force and pressure data from a relatively simple ventilated test section. Then post-test, we "correct" the realtime data for wall interferences. Unfortunately, the necessary "correction" algorithms must consider the model and wall flows and are therefore very complex. With an AWTS on the other hand, we acquire "corrected" data in real-time from a relatively complex test section. Furthermore, we find that the wall adaptation ("correction") algorithms required for an AWTS are relatively simple, so overall sof tware complexity is reduced. In effect, AWTS users trade off sof tware complexity with hardware complexity. Consequently, the overall level of system complexity remains roughly the same regardless of the test section used. However, the AWTS exhibits important advantages over a ventilated test section: the real-time data is "corrected"; these "corrections" are in some instances better; the model size can be four times larger relative to the test section size; and the flow quality is superior with solid walls.

\section{Validation Results}

\subsection{NACA 0012}

We used the well known NACA 0012 symmetrical airfoil as our classical validation model. We tested two model chords: $16.5 \mathrm{~cm}$ ( 6.5 inches) and $33 \mathrm{~cm}$ ( 13 inches). The test section height to model chord ratio is extremely small for these models, i.e. 2.0 and 1.0, respectively. Lift data shown in figure 6 , indicate how well the integrated pressures from the two models compare at Mach 0.5 and 0.7. Unfortunately, problems with the AWTS hardware restrict the angle of attack and Mach number range of the larger model. However, this limited comparison shows that the effect of model size on lift is insignificant. We also observed this favorable comparison in the detailed pressure distributions ${ }^{7}$ and the drag data.

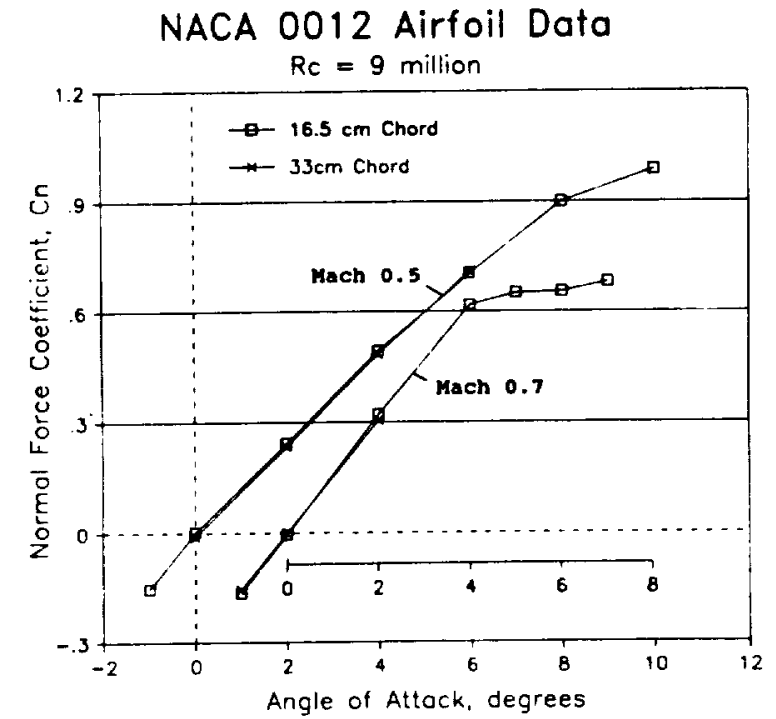

Fig. 6 Comparison of lift data from two NACA 0012 models at Mach 0.5 and Mach 0.7 .

To compare our set of NACA 0012 data with other "interference free" sets appears folly. So much data exist that almost any data set will agree with something. Consequently, we have tried an alternative way of validating our results. If the data are free of top and bottom wall interference, then classical corrections at moderate Mach numbers should be zero. Langley researchers assessed the residual interferences in the NACA 0012 data using a non-linear post-test Wall Interference Assessment/Correction Code (WIAC). Green and Newman published their results in $1987 .^{10}$ The uncorrected NACA 0012 
data compare well with theoretical free air results and only small data corrections are predicted presumably to account for sidewall effects. (Interestingly, a preliminary assessment of residual interferences in the AWTS of the ONERA T2 tunnel is very similar.) This good assessment supports a favorable comparison of our NACA 0012 data with other data sets which was recently published. ${ }^{11}$

We carried out tests with the small model up to Mach 0.78 before encountering wall curvature problems with the AWTS hardware. The NACA 0012 data confirm the poor performance of this class of airfoil at transonic speeds. This poor performance (associated with a strong shock on the suction surface) actually causes problems for the AWTS hardware much in the same way as it would for an analytical correction code. Interestingly, the better performing CAST 10 airfoil discussed in the next sub-section, could be tested up to higher Mach numbers even with a larger chord model.

We only varied the chord Reynolds number up to 30 million during these tests. Potentially, the $0.3-\mathrm{m}$ TCT has the capability of testing at over 100 million with the large model installed. Unfortunately, we have not demonstrated this capability for various reasons unrelated to the AWTS. Nevertheless, we were able to see that the Reynolds number effects on the wall adaptation are small. Typically, we require one iteration of the wall adaptation process to accommodate a change in just Reynolds number from one data point to the next. During routine testing when varying any or all of the test parameters from data point to data point, we expect up 10 two or three iterations.

The wall adaptation process does not take account of any test section length truncation. We have to theoretically minimize the effects of the finite length of the test section during the test section design process. However, in the $0.3-\mathrm{m}$ TCT, tunnel constraints restricted the AWTS length and therefore, with the large model installed, the effective test section length is only 4.3 chords. Other AWTSs operate with a test section length of over 7 chords. Consequently, we were surprised to find that the large model data were apparently unaffected by truncation effects. This observation led to some special tests aimed at finding out if other aerodynamic phenomena may be masking the truncation effects. In these tests we controlled selected upstream and downstream portions of the flexible walls as if part of the rigid tunnel circuit. We carried out these tests over the Mach number range 0.5 to 0.76 . (Free stream Mach number was always measured at the actual entrance to the test section as normal.) During these tests, we could control the effective test section length and the model position within that length, using just one model.

\section{NACA 0012 Streamlined Wall Contours}

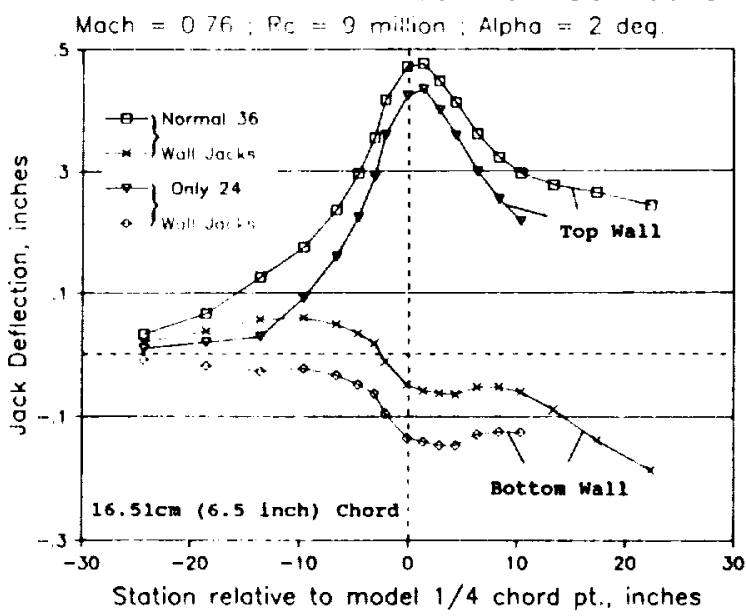

Fig. 7 Effect of simulated test section truncation on the adapted wall shapes for the same test conditions.
We found that even with the effective test section length reduced down to 3.07 chords (using only 24 of the 36 jacks for wall adaptation), truncation effects on the model were very small. $^{7}$ In addition, movement of the model relative to the effective ends of the test section had no significant effect. In all cases, we found that free stream Mach number existed at the upstream and downstream ends of the effective test section length with the walls adapted, just as normal. From these observations, previous theory ${ }^{8}$ would seem to be overly pessimistic in assessing truncation effects. However, the resulting adapted wall shapes (see figure 7) shows the increase in wall curvature we can expect when we shorten the effective length of the test section. The test section length therefore has a direct effect on wall flexibility requirements. In addition, the large wall slopes at the entrance to a short test section may lead to flow separations on the walls and add uncertainty to the measurement of the free stream conditions ahead of the model.

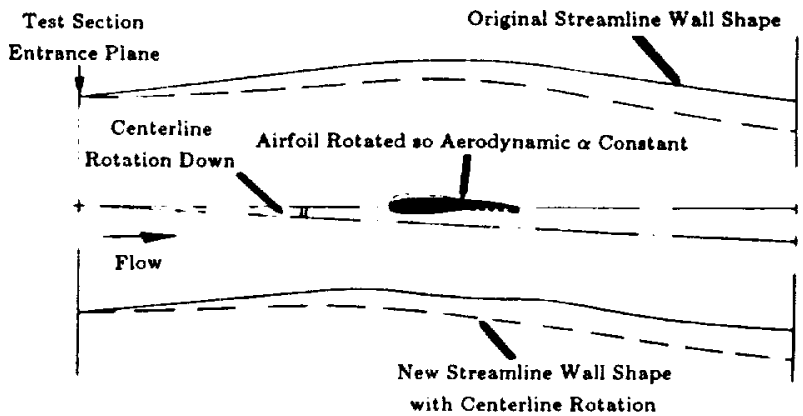

Fig. 8 Artist impression of the useful effect of centerline rotation on adapted wall shapes.

A method exists to minimize the wall slopes at the entrance to a short test section. This method ${ }^{2,12}$ involves a small intentional rotation of the tunnel centerline so that the aerodynamic $\alpha$ is less than the geometric $\alpha$. This action can significantly change the adapted wall shapes for the same test conditions. In effect we can reduce the wall slope at the test section entrance by the amount of the centerline rotation (see figure 8). However, this rotation causes the downstream ends of the flexible walls to move significantly down which may cause other problems. These problems arise from the need to smoothly connect the downstream end of the test section with the rigid diffuser. We have demonstrated the effects of centerline rotation in the $0.3-\mathrm{m}$ TCT. ${ }^{7}$ The method is now available to change the adapted wall shapes for a given set of test conditions. In addition, centerline rotation is an important means of checking that the geometric centerline and the aerodynamic centerline of the test section coincide. In our case, we observed that rotating the centerline only offsets the model lift curve slope by the angle of rotation. ${ }^{7}$ Rotation did not change the lift curve slope at three Mach numbers investigated: $0.5,0.7$ and 0.76 . We conclude that our tunnel centerline is correctly set up for normal operation. In addition, these findings further validate the wall adaptation process. The model data after wall adaptation and correction for any centerline rotation is independent of the initial wall shapes used in the adaptation procedure. The adapted wall shapes need not be unique for a given test condition.

\subsection{CAST 10-2/DOA-2}

The NACA 0012 validation tests serve only as a classical evaluation of the AWTS, since the NACA 0012 does not perform like a modern airfoil. So for a realistic evaluation of the AWTS, we have carried out further validation tests with a modern transonic airfoil section. These tests are part of cooperative agreements between NASA, NAE, ONERA, and DFVLR. Researchers chose the CAST 10 airfoil because it is a cambered supercritical airfoil, tested worldwide. The CAST 10 performance is known to exhibit the extreme sensitivity to 
Reynolds number and Mach number we have come to expect with modern airfoil sections. However in the past, researchers have experienced great difficulty in evaluating these Reynolds number effects on the airfoil data, when significant tunnel interferences are present. ${ }^{13}$ Now the modern AWTS provides a sophisticated method for real-time minimization of tunnel interferences. This capability should hopefully improve the researcher's plight. However, it is beyond the scope of this paper for us to discuss Reynolds number effects on the airfoil. We limit our comments to the claim that AWTSs eliminate top and bottom wall interference. We concentrate our comparison of data around the airfoil design conditions at Mach 0.765 . We consider these conditions to be a severe and realistic test of AWTS aerodynamic performance with this airfoil.

Two CAST 10 models were built, one in France with a $18 \mathrm{~cm}$ ( 7.09 inch) chord and the other in Canada with a $22.86 \mathrm{~cm}$ ( 9.0 inch) chord. We discuss data on both models from facilities other than the $0.3-\mathrm{m} \mathrm{TCT}$, the smaller model in the ONERA/CERT T2 tunnel with a 2-D flexible walled AWTS $^{12}$, and the larger model in the NAE $5-\mathrm{ft} \times 5-\mathrm{ft}$ Blowdown Wind Tunnel with a deep 2-D ventilated test section using perforated top and bottom walls. ${ }^{14}$

CAST 10 Airfoil Dato Mach $=0.765: \mathrm{Rc}=4$ million

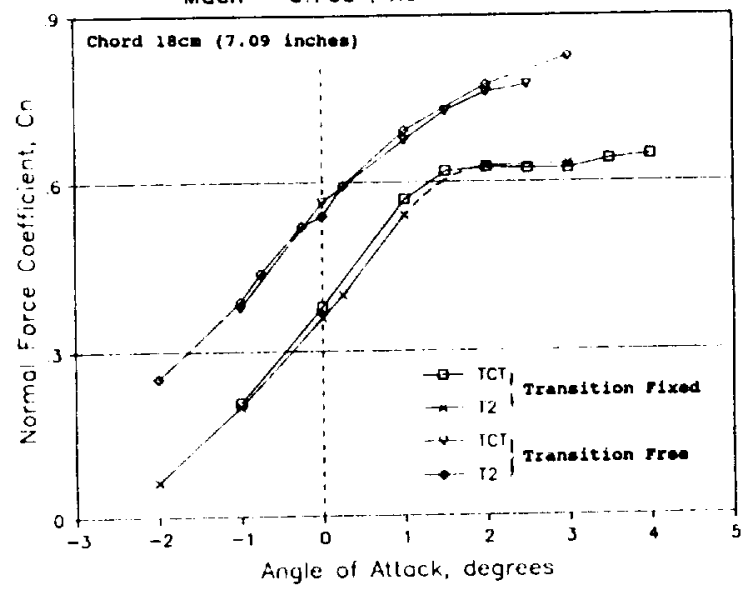

Fig. 9 Comparison of lift dala from the 0.3-m TCT and T2 tests at Mach 0.765 and 4 million Reynolds number.

We tested the smaller French model in the $0.3-\mathrm{m}$ TCT over the Mach number range 0.7 to 0.8 with chord Reynolds numbers from 4 million to 45 million. We show a comparison of lift data from $T 2^{15}$ and the $0.3-\mathrm{m}$ TCT in figure 9, for the design Mach number of 0.765 at 4 million Reynolds number with transition fixed and free. The comparisons are good particularly in the matching of $\mathrm{Cn}$. Transition was fixed at $5 \%$ chord in the T2 tunnel and $6 \%$ chord in the $0.3-\mathrm{m}$ TCT. The severe effect of transition fixing at low Reynolds number is perfectly matched in both data sets. This is quite remarkable considering the sensitivity of the airfoil to changes in tunnel turbulence and test conditions. In fact, the operation of the T2 tunnel makes it difficult to maintain the same Mach number for an $\alpha$ sweep. For example, in the $0.3-m$ TCT the Mach number variation between the data points at Mach 0.765 was about .002 . In the $T 2$, this variation was about .008 . The test section height to model chord ratios are 1.83 in the $0.3-\mathrm{m}$ TCT and 2.05 in the $\mathrm{T} 2$ tunnel. Different but similar wall adaptation procedures were used in each test. No sidewall boundary layer treatment was used in either of these tests. An associated comparison of airfoil pressure distributions is also good as shown in figure 10, for the demanding case of $M_{\infty} \simeq 0.765 ; \alpha=1.0^{\circ} ; R c=4$ million. We include in this comparison a theoretical free air pressure distribution obtained using the GRUMFOlL code. The agreement is encouraging and gives support to the claim that the AWTS data is essentially free of wall interferences.

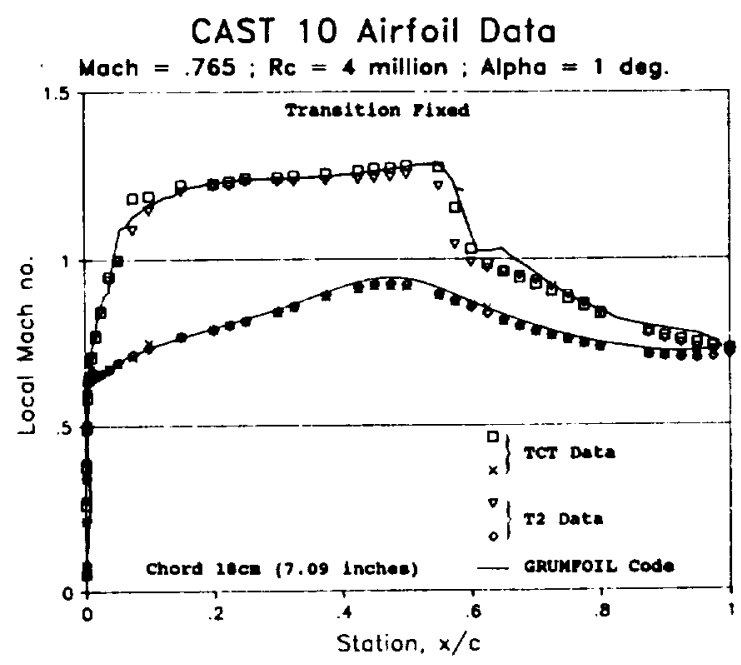

Fig. 10 Comparison of experimental and theoretical Mach number distributions for a demanding case.

In figure 11, we show the strong effect of varying Reynolds number on the T2 and $0.3-m$ TCT lift data for the demanding case: Mach 0.765; $\alpha=1^{\circ}$ with transition fixed and free. Both data sets show that at high Reynolds numbers (around 20 million) the effect of transition fixing is minimal. With transition fixed, the $T 2$ data exhibits a lower $C n$ than the $0.3-\mathrm{m}$ TCT data at the relatively high $\alpha$ considered. Interestingly, this difference reduces as Reynolds number increases. Unfortunately, the sparsity of high Reynolds number T2 data makes a more detailed assessment impossible. However, it would seem that there is a small change in the lift curve slopes between the $\mathrm{T} 2$ and $0.3-\mathrm{m}$ TCT tunnels, over the Mach number range 0.7 to 0.765 .

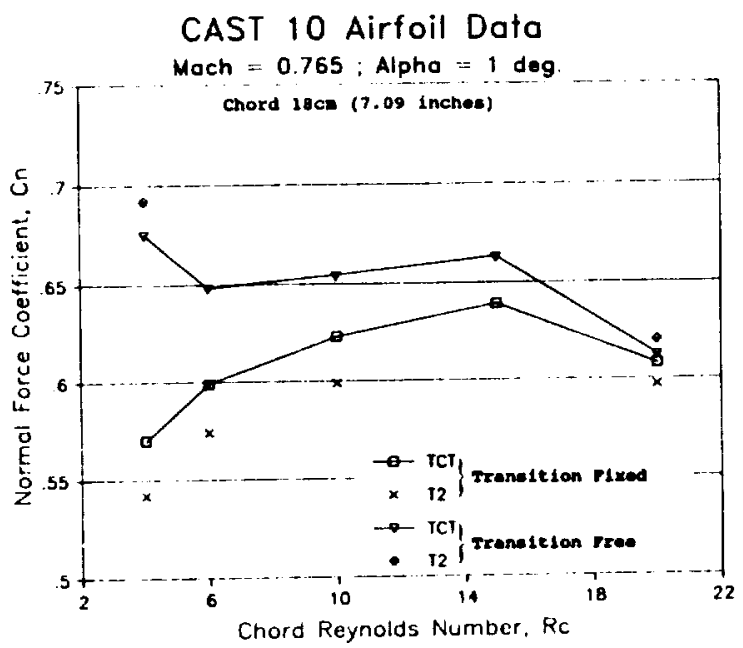

Fig. 11 The variation of T2 and TCT lift data with Reynolds number at fixed $\alpha$, with transition fixed and free.

The drag data from the two tunnels is in good agreement at low Reynolds number, when the slight differences in lift curve slope are removed from the comparison, as shown in figure 12. The comparison of lift and drag data together is very good, particularly in the matching of $\mathrm{Cd}$. At higher Reynolds numbers, the agreement is good when the flow is attached to the airfoil and the $\mathrm{Cd} s$ are well matched. However, near $\mathrm{Cn}$ the agreement is not as good regardless of the transition fixing. The exact cause, or causes, of this high Reynolds number, high lift drag disagreement is not fully understood at this time. However, we do know that the CAST 
10 is extremely sensitive to varying flow conditions, particularly at high Reynolds numbers. ${ }^{13}$ Consequently, this drag disagreement may be due to an unusual aerodynamic phenomena on the airfoil as discussed later.

CAST 10 Airfoil Dato

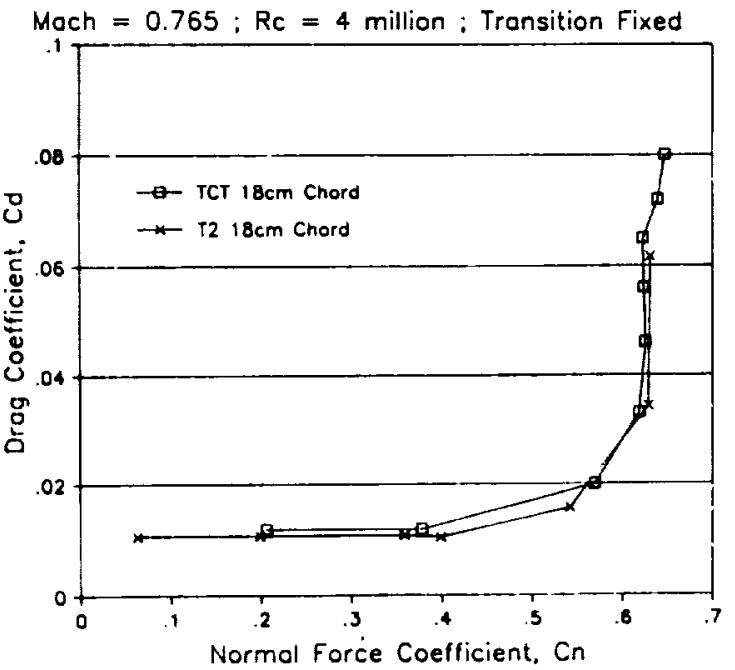

Fig. 12 Comparison of lift and drag dala from 0.3-m TCT and $T 2$ tests with the same model at Mach 0.765 and 4 million Reynolds number.

NAE tested the large Canadian model with sidewall boundary layer treatment. They then applied post-test wall interference corrections to the real-time data using the subsonic method of Mokry and Ohman. "The NAE tests had a test section height to chord ratio of 6.67 (which is very large compared with a ratio of 1.44 in the $0.3-\mathrm{m}$ TCT). The use of a small model in the NAE tunnel minimizes the top and boltom wall interference at its source, so this corrected 2-D data is probably the best available from a ventilated transonic test section. We carried out the 0.3-m TCT (NASA) tests over a Mach number range of 0.3 to 0.8 and chord Reynolds numbers from 6 million up to a record-breaking 72.4 million. ${ }^{16}$ We show a comparison of NASA and NAE lift data in figure 13 at Mach 0.765 and 10 million Reynolds number.

\section{CAST 10 Airfoil Data}

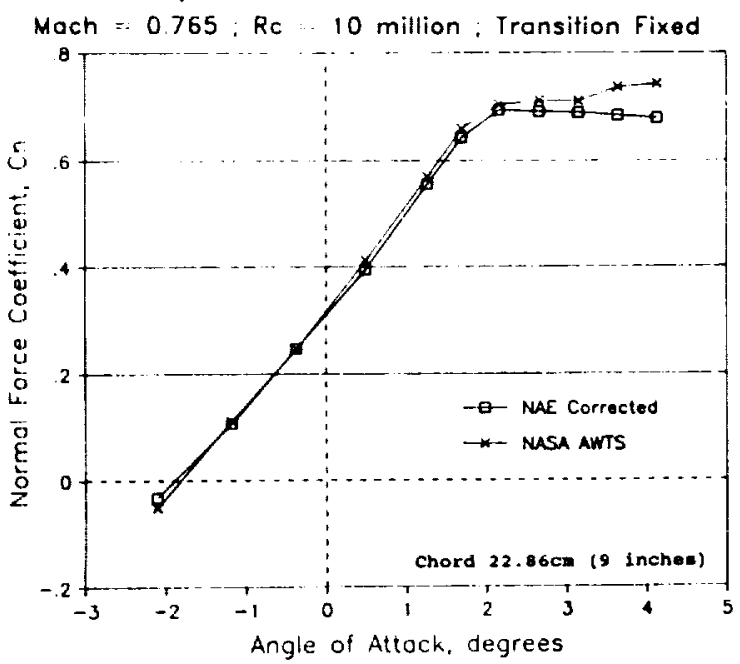

Fig. 13 Comparison of NAE and NASA lift data from the same model at Mach 0.765 and 10 million Reynolds number.
We fixed transition at $5 \%$ chord to minimize the effects of tunnel turbulence on both data sets. The comparison is very good, except for a small uncertainty in $\mathrm{Cn}_{\max }$. Detailed pressure distributions also agree very well as shown in figure 14 for a typical case: Mach $0.765 ; \alpha=1.3^{\circ} ; \mathrm{Rc}=10$ million. Also, the drag data is in excellent agreement as shown in figure 15 for the same Mach number and Reynolds number as figure 14.

\section{CAST 10 Airfoil Data}

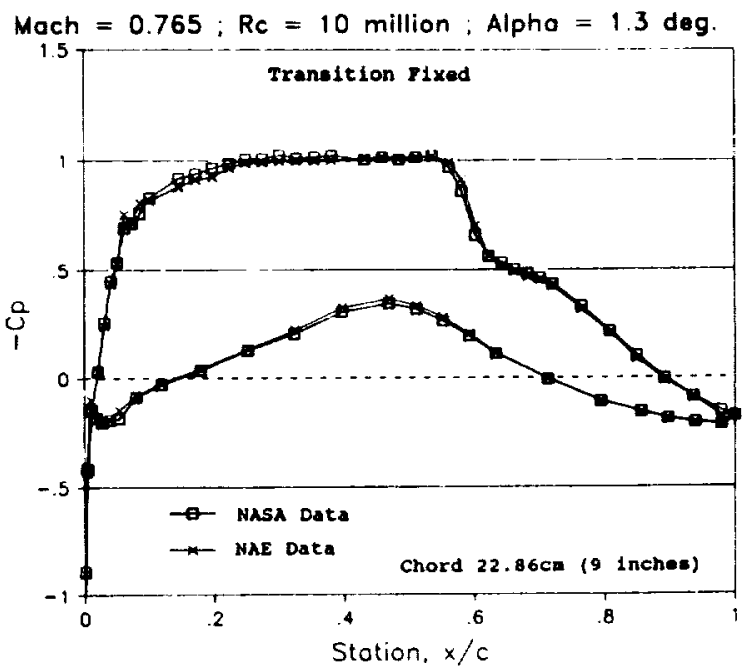

Fig. 14 Comparison of detailed pressure distributions from NAE and NASA tests of the same model.

\section{CAST 10 Airfoil Data}

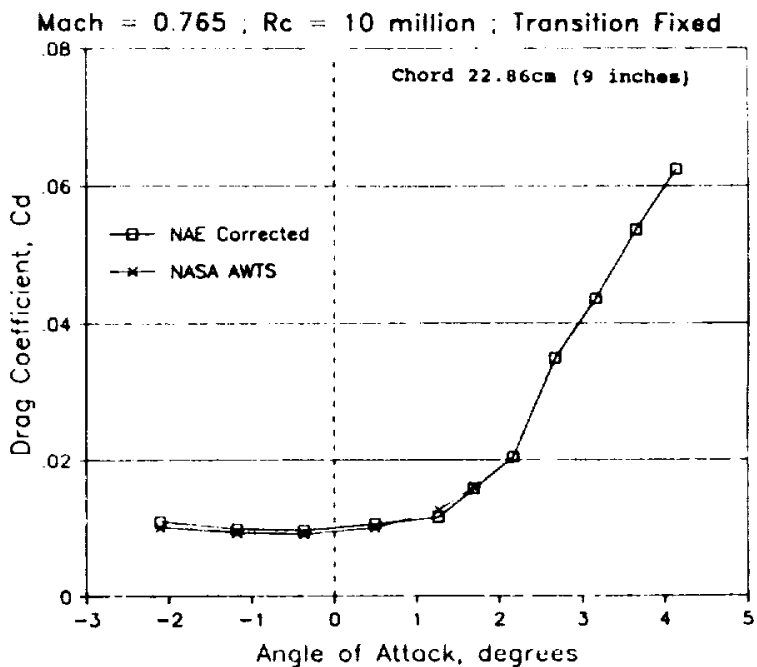

Fig. 15 Comparison of drag data from the NAE and NASA tests of the same model al Mach 0.765 and 10 million Reynolds number.

In figure 16, we highlight the spanwise flow uniformity in both the NASA and NAE tunnels. We do this by showing the associated spanwise variations of drag found in the wake surveys for representative cases: $\alpha$ approximately equal to $0.52^{\circ}$ and $1.74^{\circ}$ at Mach 0.765 . Unfortunately, T2 data cannot be included because drag data are only measured on the tunnel centerline. The NAE tests (model aspect ratio 1.67 ) had passive sidewall boundary layer removal applied around the model/sidewall junction. While, the NASA tests (model aspect ratio 1.44 ) had no sidewall boundary layer treatment. There is relatively small spanwise variation in drag found in both test sections. This finding is quite remarkable for the $0.3-\mathrm{m}$ TCT setup and is presumably due to the use of an AWTS. 
CAST 10 Airfoil Data

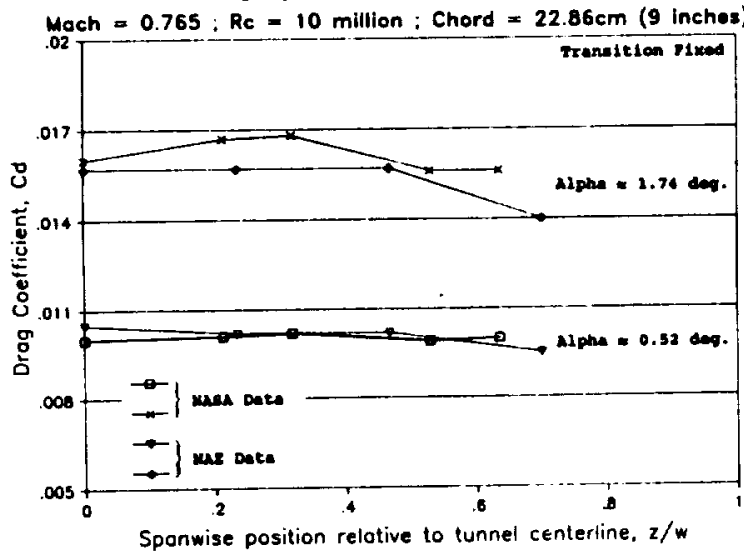

Fig. 16 The spanwise variation of drag in the NAE and NASA tests for two angles of attack at Mach 0.765 .

We show the effect of Reynolds number variation on lift during the NAE and NASA tests in figure 17, for the test conditions of $\alpha$ approximately equal to $0.45^{\circ}$ and $2.15^{\circ}$ at Mach 0.765 . There is remarkably good agreement between the two data sets over the Reynolds number range 10 to 20 million for both the moderate and high lift cases considered. Figure 17 also shows that Reynolds number effects are present up to Reynolds numbers of about 70 million.

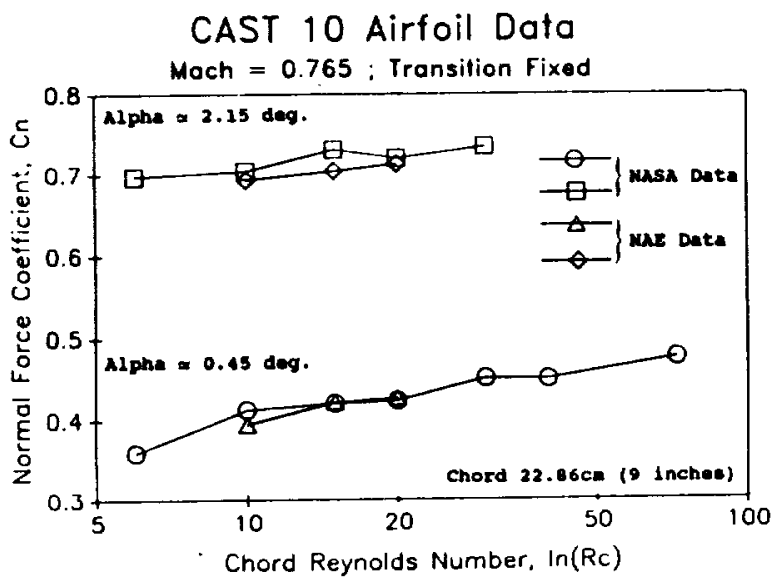

Fig. 17 Effect of Reynolds number on the lift data from the NAE and NASA tests at Mach 0.765 .

The separate data comparisons for the two CAST 10 models have interesting features. The $T 2$ data is in reasonable agreement with the NASA data on the smaller model except in drag at high Reynolds number and high lift. The NAE and NASA data on the larger model are in excellent agreement over a wide range of Reynolds numbers with some small discrepancies in $\mathrm{Cn}_{\mathrm{n}}$. When we directly compared the NASA data on the two CAST 10 models for Mach 0.765 , the lift curve slopes were in excellent agreement with the NAE data. However, there was a significant difference in $\mathrm{Cn}_{\text {max }}$ between the NASA data for the two model chords. (The Reynolds number in this direct comparison is 20 million with transition fixed.) In addition, we found that the previously mentioned discrepancy in the NASA dras data (on the smaller model at 20 million Reynolds number compared with $T 2$ data) remained when compared with the NAE and NASA drag data on the larger model. We were puzzled by these findings and decided to carry out some re-tests of both models. We repeated the performance of the smaller model in our re-test. We found that the influence of Mach number is significant around Mach 0.765 as shown in figure 18 for the case: $\alpha=1^{\circ}$; $R c=20$ million. (This finding of course justifies making data comparisons at Mach 0.765 to provide a critical examination of AWTS performance.) In addition, we found that transition fixing does have some influence, even at 20 million Reynolds numbers. However, when we re-tested the larger model, we found that this model's $\mathrm{Cn}_{\mathrm{n}}$ had in fact reduced at Mach 0.765 and 20 million Reynolds number. Consequently, there is now good agreement between the NASA data on the two CAST 10 airfoils as shown in figure 19 . The excellent agreement in lift curve slope between the NASA and NAE data indicates that the small change in lift curve slope found in the T2 data may be due to some angle of attack problem in the $\mathrm{T} 2$ tunnel.

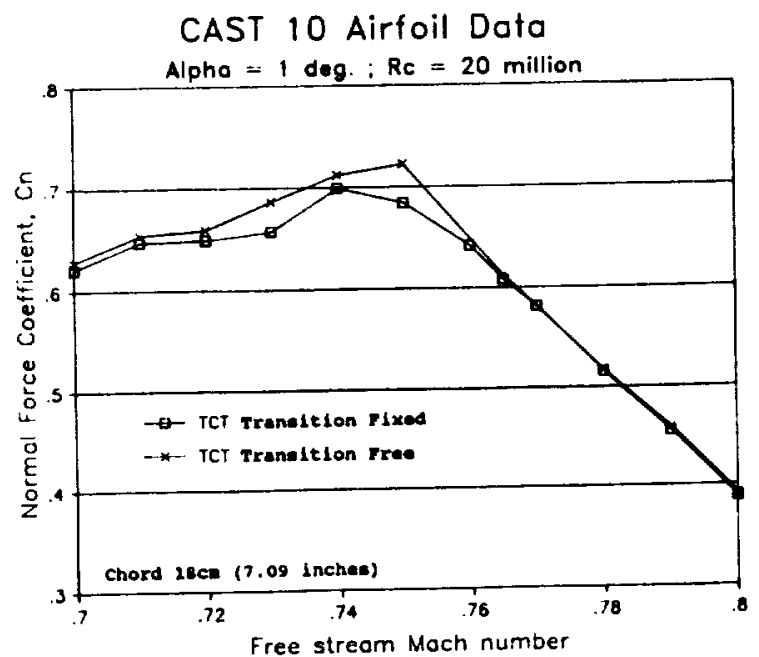

Fig. 18 Influence of Mach number on lift al a fixed $\alpha$ of $I^{\circ}$ over the Mach number range 0.7 to 0.8 .

CAST 10 Airfoil Data

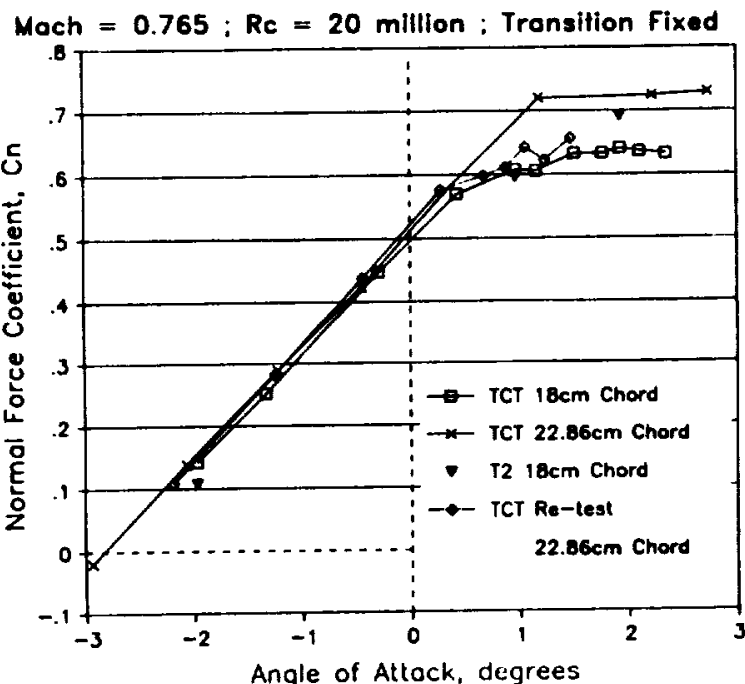

Fig. 19 Comparison of lift data from two different chord models tested in the 0.3-m TCT at Mach 0.765 and 20 million Reynolds number.

It should be noted that this direct comparison of data from the two CAST 10 models requires some adjustment of $\alpha$ The need for this adjustment arises because researchers referenced the $\alpha$ of the larger Canadian model to the model chord line and the $\alpha$ of the smaller French model to the section reference plane. The model chordline is rotated $0.88^{\circ}$ nose up relative to the section reference plane. Consequently, when comparing data from the two CAST 10 models, we reduce the $\alpha$ of the larger model data by $0.88^{\circ}$. Following our re-test of the larger model, the NASA drag data from the two models are 
now in good agreement with each other (see figure 20). Consequently, the previously mentioned drag disagreement of the NASA data (on the smaller model) with both T2 and NAE data now extends to the NASA data on the larger model.

\section{CAST 10 Airfoil Data}

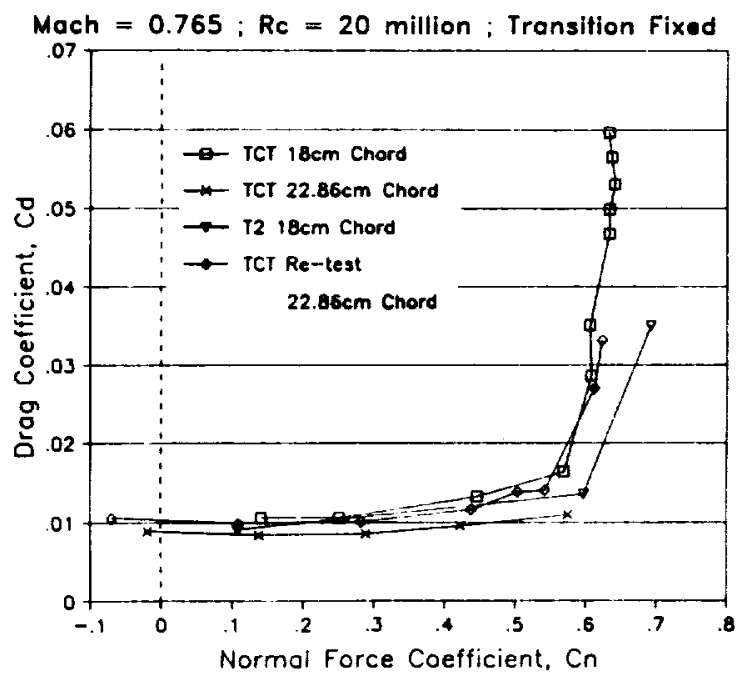

Fig. 20 Comparison of drag data for the two different chord models tested in the 0.3-m TCT at Mach 0.765 and 20 million Reynolds number.

The reason for this change in $\mathrm{Cn}_{\max }$ (and the associated drag) is probably related to the unusual aerodynamic phenomena we previously noticed in drag. The CAST 10 airfoil seems to be capable of exchanging lift for drag at high Reynolds numbers and high lift. However, the time lapse between re-tests may be significant. Our re-tests produced the best data comparisons between the two models, and the re-tests were carried out one after the other. The original NASA test of the larger model was carried out some 9 months prior to our re-test. Interestingly, NAE has experienced similar difficulties in repeating data on the larger model at these sensitive conditions, following our (NASA) re-tests. We have checked both model section co-ordinates and found them to be within manufacturing tolerances. So, we now have a situation where there is good overall agreement between various combinations of CAST 10 data, despite the sensitivity of the CAST 10 to variations in tunnel conditions. This is quite remarkable when one considers the normal difficulty of comparing sets of data between different tunnels, even when using the same model. A realistic explanation is that both sets of NASA CAST 10 data are close to the true free air result aside from the uncertainties in $\mathrm{Cn}_{\mathrm{nax}}$ and the associated drag. The NASA CAST 10 data sets do not show the unwanted effects normally associated with testing different model chords in the same tunnel. This is a benefit of using an AWTS.

We do not expect the wall adaptation process to remove all the sidewall induced interferences. Consequently, we need to consider either applying corrections to the airfoil data for residual sidewall interferences (left after wall streamlining) or use sidewall BLC to remove the interferences. We know that each set of data discussed in this paper has a different sidewall boundary layer condition at the tunnel/model junction. To investigate the sensitivity of one CAST 10 model to different amounts of sidewall boundary layer removal, we decided to integrate an existing sidewall BLC system (briefly described earlier) into our AWTS. This combination has allowed us to examine the effects of BLC on both the model and the wall adaptation process. Preliminary results indicate that passive BLC has no significant effects on the measured lift curve slope. However, the BLC can affect $\mathrm{Cn}_{\mathrm{nax}}$ if shock induced separations are likely. With the CAST $10^{\text {max }}$ it seems that Mach numbers of 0.78 and above fall into this category, i.e. after shock stall of the model. The effect of BLC at Mach 0.765 is not significant and so sidewall interferences are unlikely to cause the changes in $\mathrm{C} \mathbf{n}_{\text {ax }}$ we have observed experimentally. It would seem that the use of large models in AWTSs normally introduces some intrinsic correction of sidewall boundary layer effects until separations occur. The CAST 10 data comparisons do not strongly advocate the need for residual corrections but we realize this may not always be the case. The use of the BLC system with the wall adaptation process is routine. The successful use of the BLC system gives the 0.3-m TCT an extremely useful capability for future studies of Reynolds number and sidewall boundary layer effects and interactions.

\section{Operational Highlights}

The operation of an AWTS in a cryogenic environment may appear daunting. The test section walls must stay flexible and the wall jacks free when operating at temperatures below $100 \mathrm{~K}$ for several hours (see figure 21 ). Nevertheless, the $0.3-$ m TCT AWTS has performed remarkably well. We have successfully operated the AWTS over the entire operating envelope of TCT. The only problems encountered were wall jack binding during rapid changes of temperature when problems are also encountered with the angle of attack and rake setting mechanisms. Anyway, we can easily avoid these problems by suitable operating procedures.

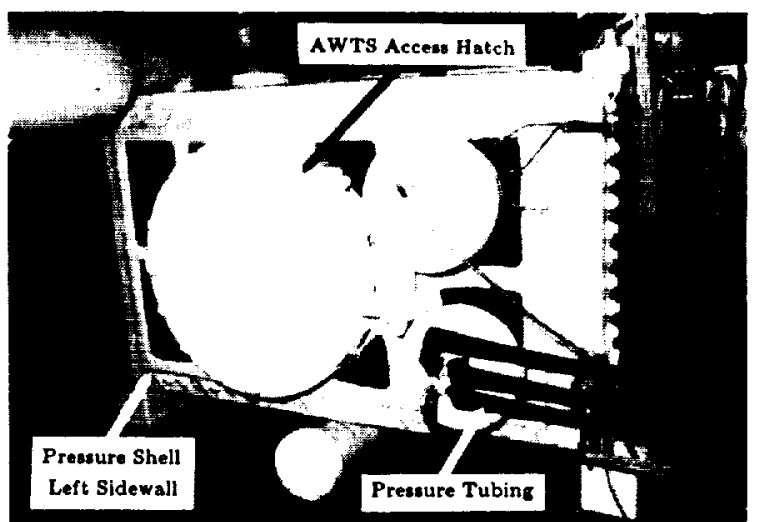

Fig. 21 View of the frost build-up on the pressure shell surrounding the 0.3-m TCT AWTS after a typical day of testing at cryogentic temperatures.

The substantial amount of material expansion and contraction in the AWTS during cryogenic operation has not given rise to any problems. We know that unmeasurable movements of the flexible walls occur and the wall position transducers drift. However, we cannot measure any influence of temperature on the model data with test conditions held constant. We anticipate some self-correction of the wall movement is occurring.

We have automated the operation of the AWTS and have written the control software for both production and research testing. ${ }^{17}$ Non-expert use of the facility is possible if AWTS hardware problems are not encountered. Nevertheless, the limitations of the AWTS are known ${ }^{7}$ and routine operation is possible. Typically, we acquire "corrected" real-time data after less than 2 minutes of wall adaptation. Already a variety of research programs have utilized the unique capabilities of the 0.3-m TCT AWTS. We can take up to 50 data points (each with full wall adaptation) in one 6-hour testing shift.

The wide range of chord Reynolds numbers achieved in the AWTS (up to 72.4 million) is remarkable. The influence of Reynolds number on the adaptation process is minimal compared to the Mach number effects. Nevertheless, the Reynolds number effects remain airfoil dependent and could be significant in the future. 
We have tested over a wide range of model lift with normal force coefficients up to 1.53 with the walls streamlined. We encountered wall movement problems when we combine high lift conditions with a very large model. The maximum wall movement we have recorded in a successful wall adaptation is $3.76 \mathrm{~cm}$ (1.48 inches), which is well within the allowable $7.62 \mathrm{~cm}$ ( 3 inches) of upward jack travel. We find that the wall movement in this case is limited by the jack loads. We have observed that the AWTS hardware limitations are less likely to be a problem if the model chord is less than $22.86 \mathrm{~cm}$ ( 9 inches). The levels of lift successfully accommodated in our AWTS are considerably greater than for any other AWTS. Hardware problems aside, we treat data points at high lift as routine. So far the significant wall slopes associated with high lift do not pose any aerodynamic problems. In addition, we are pleased that we did not observe any wall induced hysteresis effects in the model data through stall. The model data after wall adaptation is independent of any wall shapes set in the adaptation process.

Despite hardware problems, we have been able to cover most of the test conditions required in 2-D testing up to drag rise Mach numbers. Generally, the Mach number range of the AWTS is dependent on model size within wall curvature restrictions. So far, we have not come up against any Mach number limitations due to our wall adaptation process, i.e. when the walls become sonic with the walls nearly streamlined.

We have seen that the adaptive wall testing technique is tolerant of imperfections in the test section shape. In fact, we have been forced to operate for some time with one wall jack under the model position completely disconnected. In the 0.3 $m$ TCT AWTS, the wall settings accuracy is lower than found in other AWTSs due to hardware restrictions and available instrumentation. Nevertheless, the wall setting accuracy in the $0.3-\mathrm{m}$ TCT seems adequate for 2-D testing. However, problems of accurately setting the flexible walls to a zero movement datum combined with a slow deterioration of the flexible walls themselves has given rise to some repeatability problems. Also, local wall imperfections did not allow us to experimentally find the reference wall shapes for constant Mach number in an empty test section. However, with the relaxed wall setting accuracy, divergent flat wall shapes suffice for making an allowance for the boundary layer growth on all four walls. The important fact here is that in 2-D testing, the model influence on the wall pressures is very large compared to the effect of local wall imperfections.

\section{Lessons Learnt to Point to the Future}

We have learnt much from our 2 years of operational experience with the $0.3-\mathrm{m}$ TCT AWTS. We have now taken over 2000 data points, each with the walls fully adapted. The design of our AWTS is not optimum. It works remarkably well considering the operating environment. However, we hope others will learn from the mistakes we have made along the way. We consider the following remarks summarize lessons learnt with our AWTS:

1) An AWTS must be designed to accommodate realistic wall shape requirements.

2) The flexible walls should be easily removable for repair or replacement.

3) At least one of the AWTS sidewalls should be completely removable for access.

4) The jack mechanisms should be designed to allow complete on-site inspection.

5) There should be redundancy in the critical measurements of wall position.

6) The jack mechanisms need a reliable flat datum condition to reference all movement.

7) The flexible walls need to bend to at least a $40 \mathrm{~cm}$ (15.75 inches) radius of curvature in our AWTS.
The consequences of poor design are limited test envelopes, costly down times for repair, and inefficient operation. Our most pressing need in AWTS hardware is new flexible walls designed for flexibility as found in other AWTSs. ${ }^{7}$ With new walls, we will be able to expand the $0.3-\mathrm{m}$ TCT test envelope for routine use of very large models with the airfoil chord equal to the test section height.

We chose a vertical sweeping drag rake for our AWTS, as used in a ventilated test section. Unfortunately, we have experienced difficulties in stabilizing Mach number during wake surveys at transonic Mach numbers when the wake is large due to flow separations. This difficulty causes accurate wake surveys to be long and tedious. We conclude that vertical sweeping drag rakes do not work well in solid walled test sections at transonic speeds. The item now pacing our tunnel productivity is the drag survey. We need to rethink our drag surveying concept to compress the time attributed to each data point if we are to approach the previous $0.3-\mathrm{m}$ TCT productivity of $100-150$ points per testing shift.

In terms of software, we have now identified the essential requirements for any AWTS control system. ${ }^{7}$ We now know that our system is not ideal due to the use of inappropriate computer systems. However, we have coaxed our system to perform remarkably well even with non-expert users. We continue to improve our control system as new hardware and software become available, making the system more user-friendly. We now view the different tasks involved in the control system as separate sub-systems. A sub-system may ideally require a separate workstation or mircoprocessor depending on the operator interface required. Computation time is not a concern in the wall adaptation process which usually takes less than 2 minutes. Our pacing item in the wall adaptation process is wall movement. We can minimize the time due to movement by improving our estimation of the model performance at a given test condition, so the flexible wall shapes are almost adapted at the beginning of each wall adaptation process.

We are very happy with the performance of our wall adaptation process itself. The wall adjustment theory of Judd et al continues to provide good service. The theory is well documented and relatively uncomplicated. ${ }^{2}$ However, we feel that it will eventually be possible to test beyond the capabilities of the theory, when we incorporate hardware improvements in our AWTS. In particular, we anticipate problems when we encounter significant wall slopes required for streamlining around very large models and also when we encounter sonic flow reaching the nearly streamlined walls. Researchers have already found solutions to both these problems by suitable modification of the existing wall adjustment theory. ${ }^{18}$

We will continue to perfect our 2-D experimental testing techniques based on adaptive wall technology. Now that a major source of the tunnel interferences is eliminated, we are better able to examine other smaller sources of interference such as the sidewall boundary layers. In the future, we fully intend to use all the hardware and sof tware tools available to us to minimize the small residual interferences present in our transonic 2-D data.

\section{Conclusions}

1. The AWTS is routinely operated over the entire cryogenic operating envelope of the $0.3-\mathrm{m}$ TCT.

2. The validation data confirms that the $0.3-\mathrm{m}$ TCT 2-D data is essentially free of wall interferences.

3. We have extended the operating envelope for AWTSs into the realms of fuil scale Reynolds numbers and high lift. 
4. We have learnt important lessons about AWTS design from our testing experience. We now know how to improve our capability to test very large models routinely.

5. Non-expert use of AWTS is possible with suitable control system design.

6. We have realized the advantages of an AWTS for 2-D testing within known hardware limitations.

7. We have successfully integrated a passive BLC system with the 0.3-m TCT AWTS.

8. The $0.3-\mathrm{m}$ TCT is an ideal research tool to examine Reynolds number and sidewall boundary layer effects with wall interferences minimized and a large Reynolds number capability.

9. The 0.3-m TCT with an AWTS and sophisticated BLC potential is the most advanced 2-D wind tunnel facility anywhere.

\section{References}

1. Bailey, A.; and Wood, S. A.: Further Development of a High-Speed Wind Tunnel of Rectangular Cross-Section. British ARC R\&M 1853, September 1938, 16 pp. In: Technical Report of the Aeronautical Research Committee, 1938, Vol. 2, pp. 753-768.

2. Goodyer, M. J.: The Self Streamlining Wind Tunnel. NASA TM-X 72699, August 1975, 45 pp.

3. Tuttle, M. H.; and Mineck, R. E.: Adaptive Wall Wind Tunuels - A Selected, Annotated Bibliography. NASA TM 87639, August $1986,53 \mathrm{pp}$

4. Holder, D. W.: The High-Speed Laboratory of the Aeronautics Division, N.P.L. - Parts I, II and III. British ARC R\&M 2560, December 1946.

5. Kilgore, R. A.: The NASA Langley 0.3-m Transonic Cryogenic Tunnel. Presented as Paper no. 13 of the AGARD-FDP/VKI Special Course on Cryogenic Technology for Wind Tunnel Testing held at the von Karman Institute, Rhode-Saint-Genese, Belgium, April 22-26, 1985. In: AGARD-R-172, 1985, $15 \mathrm{pp}$.

6. Ladson, C. L.; and Ray, E. J.: Evolution, Calibration, and Operational Characteristics of the TwoDimensional Test Section of the Langley 0.3-Meter Transonic Cryogenic Tunnel. NASA TP 2749 , September 1987, $170 \mathrm{pp}$.

7. Wolf, S. W. D.: Evaluation of a Flexible Wall Testing Technique to Minimize Wall Interferences in the NASA Langley 0.3-m Transonic Cryogenic Tunnel. AIAA Paper no. 88-0140. Presented at the AlAA 26th Aerospace Sciences Meeting, Reno, Nevada, January 11$14,1988,11 \mathrm{pp}$.

8. Judd, M.; Goodyer, M. J.; and Wolf, S. W. D.: Application of the Computer for On-Site Definition and Control of Wind Tunnel Shape for Minimum Boundary Interference. Presented as Paper no. 6 at AGARD Specialists" Meeting on "Numerical Methods and Windtunnel Testing," Rhode-Saint-Genese, Belgium, June 23-24, 1976, $14 \mathrm{pp}$.

9. Wolf, S. W. D.; and Goodyer, M. J.: Predictive Wall Adjustment Strategy for Two-Dimensional Flexible Walled Adaptive Wind Tunnel. A Detailed Description of the First One-Step Method. AASU Memo 85/12, January 1986. NASA CR-181635, January 1988 .
10. Green, L. L.; and Newman, P. A.: Transonic Wall Interference Assessment and Corrections for Airfoll Data From the 0.3-Meter TCT Adaptive Wall Test Section. AlAA Paper 87-1431. Presented at the AIAA 19th Fluid Dynamics, Plasma Dynamics and Lasers Conference, Honolulu, Hawaii, June 8-10, 1987, 24 pp.

11. McCroskey, W. J.: A Critical Assessment of Wind Tunnel Results for the NACA 0012 Alrfoil. Presented as Paper no. 1 at the AGARD Fluid Dynamics Panel Symposium on Aerodynamic Data Accuracy and Quality: Requirements and Capabilities in Wind Tunnel Testing, Naples, Italy, September 28-October 2, 1987, 20 pp.

12. Chevallier, J.-P.; Mignosi, A.; Archambaud, J. P.; and Seraudie, A.: T2 Wind Tunnel Adaptive Walls--Design, Construction, and Some Typical Results. La Recherche Aerospatiale (English Edition), no. 4, July/August 1983, $19 \mathrm{pp}$.

13. Stanewsky, E.; Demurie F.; Ray, E. J.; and Johnson, C. B.: HIgh Reynolds Number Tests of the CAST 102/DOA2 Transonic Airfoll at Amblent and Cryogenic Temperature Conditions. Presented as Paper no. 10 at AGARD Fluid Dynamics Panel Symposium on "Wind Tunnels and Testing Techniques," Cesme, Turkey, September 26-29, 1983, 13 pp.

14. Chan, Y. Y: WInd Tunnel Investigation of CAST 102/DOA-2 12\% Supercritical Alrfoil Model, Phase I. LTR-HA-5X5/0162, May 1986

15. Seraudie, A.; Blanchard, A.; and Breil, J. F.: Test Report of the CAST 10 with Fixed Transition, Obtained in the Cryogealc Transonic Wind Tunnel T2 Equipped with Adaptive Walls. ONERA R. T. OA no. 63/1685, August 1985. In English.

16. Mineck, R. E.: Wall Interference Tests of a CAST 102/DOA 2 Airfoil in an Adaptive-Wall Test Section. NASA TM 4015, November 1987,98 pp.

17. Wolf, S. W. D.: Wall Adjustment Strategy Software for Use with the NASA Langley 0.3-Meter Transonic Cryogenic Tunnel Adaptive Wall Test Section. NASA CR-181694, August 1988.

18. Lewis, M. C.: The Status of Two-Dimensional Testing at High Transonic Speeds in the University of Southampton Transonic Self-Streamlining Wind Tunnel. NASA CR 3919, October 1985, 56 pp. 


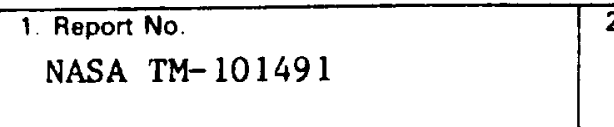

\section{Title and Subtitle}

2. Government Accession No.

3. Recinient's Catalog No.

Highlights of Experience with a Flexible Walled Test Section in the NASA Langley 0.3-Meter

Transonic Cryogenic Tunnel

\section{Author(s)}

Stephen W. D. Wolf and Edward J. Ray

9. Performing Organization Name and Address

NASA Langley Research Center

Hampton, VA 23665-5225

12. Sponsoring Agency Name and Address

National Aeronautics and Space Administration

Washington, DC 20546-0001

5. Report Date

Septemiber 1988

6. Performing Organization Code

8. Pertorming Organization Repon No.

10. Work Unit No

505-61-01-02

11. Contract or Grant No.

13. Type of Peport and Period Covered

Technical Memorandum

14. Sponsoring Agency Code

\section{Supplementary Notes}

Stephen W. D. Wolf: Vigyan Research Associates, Inc., Hampton, Virginia.

Presented at the AIAA 15th Aerodynamic Testing Conference, San Diego, California, May 18-20, 1988. (AIAA Paper No. 88-2036)

\section{Abstract}

The unique combination of adaptive wall technology with a continuous flow cryogenic wind tunnel is described. This powerful combination allows wind tunnel users to carry out two-dimensional (2-D) tests at flight Reynolds numbers with wall interferences essentially eliminated. WE highlight validation testing to support this claim using well tested symmetrical and cambered airfoils at transonic speeds and high Reynolds numbers. We briefly describe the test section hardware which has four solid walls, with the floor and ceiling flexible. We outline the method of adapting/shaping the floor and ceiling to eliminate top and bottom wall interference at its source. The highlights of our testing expertence involve discussion of data comparisons for different size models tested by us and others in several sophisticated 2-D wind tunnels. In addition, we examine the effects of Reynolds number, testing uniqueness of the adapted wall shapes and the effects of sidewall boundary layer control. Our 2 years of operational experience with the adaptive wall test section hardware and 1 ts associated control system has taught us important lessions about design and operating procedures. We conclude that the 0.3-m TCT is now the most advanced \begin{tabular}{l|l}
$2-D$ regearch facility anywhere. & 18. Distribution Statement
\end{tabular}

Adaptive walls Unclassified - Unlimited

Wall Interference Cryogenic wind tunnel

Subject Category - 09

Transonic flows

19. Security Classif. Lof this report

Unclassified
20. Security Classit. Iof this pagel

Unclassified

21. No. of pages
11

22. Price

$\mathrm{AO} 2$ 

